\title{
A Política Externa nas Eleições Presidenciais de 2014: análise da agenda dos principais candidatos
}

Foreign Policy in the presidential elections of 2014: Agenda Analysis of the leading candidates

Francine Magalhães Vaz ${ }^{1}$

\section{RESUMO}

Visando observar como o tema Política Externa é tratado nas campanhas eleitorais, o escopo deste trabalho busca analisar as campanhas dos principais candidatos à Presidência da República no pleito de 2014. A hipótese levantada e concluída nesse artigo é a de que o tema Política Externa mantém-se como assunto secundário nas propostas apresentadas pelos presidenciáveis em suas agendas públicas e de forma distinta entre as propostas dos mesmos.

Palavras-chave: Política Externa, Eleições Presidenciais, Brasil.

\begin{abstract}
This article analyzes how the main candidates of 2014's Presidential Election dealt with Foreign Policy's issues in electoral campaigns. The research concludes that Foreign Policy's thematic remains as a secondary concern at nominees' public agenda and changes among the campaigns.
\end{abstract}

Key-words: Foreign Policy, Presidential Elections, Brazil.

\section{INTRODUÇÃO}

A Política Externa de um país é formulada a partir do resultado da soma de seu vínculo político interno com o estrangeiro, sendo-lhe associada uma gestão pública de atividades, formuladas e aplicadas por representantes do Governo. O Brasil, país com política pública voltada tradicionalmente para dentro, historicamente

1 Bacharel em Relações Internacionais pela Universidade Federal de Pelotas (Pelotas/RS, Brasil). 
habituado à autonomia devido às suas condições geográficas, apresenta sua internacionalização ainda não absorvida por completo. Para Visentini (2013), no começo do século XXI houve o reconhecimento do Brasil como potência emergente e o governo substituiu a passividade anterior e buscou alianças fora do Hemisfério Norte, como forma de ampliar seu poder de influência.

\begin{abstract}
A atuação brasileira no exterior ainda é em sua maior parte desconhecida pelos brasileiros, situação que pode ser refletida nas propostas e debates dos políticos em época de eleição. Tradicionalmente, as Relações Internacionais do Brasil foram construídas de acordo com as diretrizes do Barão de Rio Branco e com grande priorização de parcerias com países desenvolvidos (ONUKI, 2011, P. 3).
\end{abstract}

Atualmente, apresenta relações multilaterais com diversos países, sendo tanto do Sul ou Norte global. País com características diplomáticas e conciliadoras, não participa energicamente em questões de Segurança, assim como não costuma impor sanções a algum Estado. Ainda é relativamente pequena, mas em constante crescimento, a quantidade de material englobando em sua totalidade os candidatos e suas propostas, motivações e planos de ação para o Brasil no âmbito internacional, um dos motivos pelo qual surgiu o interesse em pesquisar sobre o tema. Além disso, destaca-se uma agenda de pesquisa recente, que procura trabalhar a Política Externa como Política Pública e como a área é passível de democratização.

As campanhas analisadas serão as dos três principais candidatos ao primeiro turno das eleições presidenciais de 2014, sendo eles Aécio Neves (PSDB)², Dilma Rousseff (PT) ${ }^{3}$ e Marina Silva (PSB) ${ }^{4}$. Metodologicamente, serão utilizadas técnicas de pesquisas documentais, de caráter qualitativo, sobre uma seleção de livros, ensaios e artigos científicos e jornalísticos que possam embasar uma observação da relação de diversos temas, como a percepção da opinião pública brasileira sobre

\footnotetext{
2 MUDA BRASIL (PSDB / PMN / SD / DEM / PEN / PTN / PTB / PTC / PT do B

3 COLIGAÇÃO COM A FORÇA DO POVO (PT / PMDB / PSD / PP / PR / PROS / PDT / PC do B / PRB)

$4 \quad$ UNIDOS PELO BRASIL (PHS / PRP / PPS / PPL / PSB / PSL)

Conjuntura Global, vol. 5 n. 1, jan./abr., 2016, p. 168-188.
} 
a política externa do país. A escolha do material foi feita através de pesquisas que visaram a relação das eleições brasileiras com as possíveis diretrizes de atuação do Brasil no exterior.

0 presente trabalho visa analisar as campanhas eleitorais à Presidência da República durante o ano de 2014, observando as similaridades e diferenças entre as ideias dos principais candidatos quanto à Política Externa e, uma vez em que aparecem, se é possível observar a direção, rupturas e continuidades com a linha de atuação do Governo. A relevância dada pelos mesmos ao tema de acordo com o demonstrado por eles será analisada através de seus planos de governo oficiais, debates e entrevistas. Desta forma, o artigo procurou responder a seguinte pergunta: "Quais foram as diretrizes sobre Política Externa dentro dos planos de atuação dos candidatos às eleições Presidenciais e quais foram as principais divergências entre eles?" A hipótese principal se baseia na ideia de que o tema ainda é tratado como secundário pelos candidatos, assim como pela imprensa, despertando pouco interesse no eleitorado, e que, mesmo que apareçam de forma quase despercebidas nas campanhas, as diretrizes de Política Externa divergem entre os candidatos, ou seja, cada coligação apresenta prioridades distintas a serem buscadas pelo Brasil em relação à agenda global.

A pesquisa será dividida em duas grandes seções, sendo a primeira uma revisão teórico-conceitual sobre os temas, na qual a Política Externa Brasileira (PEB) é relacionada com Eleições, assim como Política Pública com a relação do interno/externo, discutida por uma abordagem relativamente nova na Política Externa na sua fronteira com a Ciência Política. A segunda será a análise propriamente das campanhas dos candidatos, com observação direta dos debates realizados por emissoras televisivas brasileiras, leitura dos planos de governo enviados pelos candidatos ao Tribunal Superior Eleitoral, entrevistas concedidas pelos mesmos e artigos publicados por profissionais da área em mídias diversas.

Assim, o objetivo geral do trabalho é observar como a Política Externa foi tratada pelos candidatos com maior intenção de voto, relacionando-a com o Conjuntura Global, vol. 5 n. 1, jan./abr., 2016, p. 168-188. 
conhecimento empírico dos eleitores, como a proposta de torná-la uma agenda de Política Pública. As propostas e objetivos das lideranças para a ação brasileira frente aos BRICS e ao MERCOSUL, assim como importantes assuntos da agenda internacional, como Segurança, relações com países desenvolvidos e Cooperação Sul-Sul são preponderantes na projeção internacional do Brasil, tornando-as material chave nesse projeto.

\section{Política Externa: decisão e participação}

A vinculação entre Opinião Pública e Política Externa teve destaque com a Guerra do Vietnã. Com seu impacto na sociedade americana, o tema da Opinião Pública passou para o primeiro plano, marcando definitivamente sua relevância no

processo decisório em Política Externa. Surgiram, mesmo antes do conflito, diversos trabalhos de autores estadunidenses relacionando a Opinião Pública com a Política Externa dos Estados Unidos. Com a publicação de Domestic Sources of Foreign Policy (1967), Rosenau reforçou a premissa de que atores e fatores domésticos não eram menos relevantes para a formulação e o conteúdo da Política Externa do que o contexto internacional, somando esforços à sua contribuição anterior em que já apontara a necessidade de desenvolver uma teoria que desse conta dos diferentes níveis de análise para explicar a Política Externa dos Estados.

A PEB sempre se caracterizou por ser formulada estritamente pelo Itamaraty, não havendo interesse em uma agenda pública dos debates. Formulada e executada pelo Ministério de Relações Exteriores (MRE), com maior ou menor protagonismo da Presidência da República, ela foi, tipicamente, uma política produzida em situação de insulamento burocrático. Assim, sua natureza de Política de Estado - coerente, estável, suprapartidária e pouco sensível às mudanças de governo - foi explicada pelo predomínio, no processo de sua definição e implementação, do Itamaraty, agência estatal com forte espírito de corpo, memória institucional, treinamento especializado e competência específica. Existem teorias 
que apontam essa caracterização justamente pela existência do MRE e sua condição de Política de Estado, traçada por profissionais especializados e de acordo com as diretrizes do Itamaraty e não partidária e, assim, não fazendo parte das propagandas políticas e debates eleitorais.

De acordo com Cardoso (2012), “ainda que difícil, o melhor caminho a ser trilhado parece ser aquele que vise o estabelecimento de canais de comunicação entre os formuladores de política externa e indivíduos da sociedade civil”, para a definição, atualização e adequação da política externa aos genuínos interesses nacionais, atentos aos riscos do predomínio de interesses setoriais de grupos com maior força e organização, e da sobreposição de valores partidários próprios do grupo que ocupa circunstancialmente o poder sobre os valores permanentes da sociedade. Assim, a Política Externa poderia ser formulada e aplicada de acordo com o mais próximo que se pode citar de um interesse público, passível de democratização, podendo ser vinculada através de uma relação direta entre o âmbito interno e o externo.

A existência de correlações entre as políticas interna, externa e internacional possui base teórica desenvolvida por Robert Keohane e Joseph Nye em fins da década de 1970. Na obra, avançou-se no conceito da "interdependência", em que os Estados dependem de diferentes atuações e jogos de interesses, nas diversas resoluções e atitudes com o exterior. Helen Milner, em sua obra Interest, Institutions and Information (1997), traz uma proposta sobre como repensar essas atuações. Para isso, a autora relaciona momentos da produção teórica que tratam a relação entre as políticas interna, externa e internacional e, a partir da metodologia dos jogos de dois níveis de Robert Putnam, procura incorporar a este modelo o papel de outros atores além dos Estados.

Também de acordo com Milner (1997, p. 3), em um primeiro instante (décadas de 1960 e 1970), a Política Externa dos estados era vista como um resultado da Política Interna. Em seguida (décadas de 1970 e 1980), houve a revisão dessa concepção, que passou a dar destaque para as influências 
internacionais no âmbito interno e vice-versa. Por fim (1980-1990), sob a influência dessas teorias, Robert Putnam sistematizou a teoria dos jogos de dois níveis. Tais referências teóricas apontadas por Milner também encontram reflexos na produção acadêmica brasileira quanto à concepção de política externa. Há políticos, com suas ações voltadas para a Política Interna ou Externa, que

[...] ficam entre esses dois polos em uma área que chamo de poliarquia, uma estrutura mais complexa que tanto a anarquia quanto a hierarquia, em que as relações são modeladas mais como uma rede. Nenhum grupo individual fica no topo; o poder sobre ou a autoridade pela produção de decisões é compartilhada, frequentemente de modo desigual. As relações entre grupos na poliarquia acarretam relações recíprocas e/ou a divisão de distintos poderes entre os grupos. Meu argumento central é que os estados não são atores unitários, isto é, eles não são estritamente hierárquicos mas são poliárquicos, compostos por atores com preferências variáveis e que compartilham o poder na tomada de decisão (MILNER, 1997, p. 11).

Nesse sentido, para a poliarquia, comprometer-se com a internacionalidade figurou-se como algo crucial, percebendo-se a Política Interna e a Externa como integrantes de uma "disputa doméstica pelo poder" (Ibidem), com a principal intenção de um empenho internacional.

As eleições de 2014, assim como qualquer outra, possibilitariam uma continuidade das diretrizes já seguidas pela então Presidenta Dilma Rousseff ou um novo enfoque estratégico, caso algum candidato da oposição ganhasse o pleito. Para observar como o resultado da votação influenciaria (ou não) na política exterior brasileira, deve-se analisar a relação do âmbito com o outro. Dentre os enfoques teóricos desenvolvidos para lidar com as interações entre o externo e o interno, no interior dos regimes democráticos liberais, uma das formulações mais instigantes e com o potencial de melhores resultados de análise é a teoria dos jogos de dois níveis, do estadunidense Robert Putnam. A disputa política de várias negociações internacionais pode ser facilmente concebida como um jogo de dois níveis. 
No nível nacional, os grupos domésticos buscam seu interesse pressionando o governo a adotar políticas favoráveis a seus interesses e os políticos visam o poder constituindo coalizões entre esses grupos. No nível internacional, os governos nacionais visam expandir suas próprias habilidades de satisfazer as pressões domésticas, enquanto minimizam as possíveis consequências das ações do exterior. Nenhum dos dois jogos pode ser ignorado pelos tomadores de decisão, pois seus países permanecem ao mesmo tempo interdependentes e soberanos (PUTNAM, 1988, p. 151).

Cada liderança política nacional está presente em ambos os tabuleiros do jogo. Para o teórico, do outro lado do tabuleiro internacional sentam as contrapartes estrangeiras, ao lado das quais sentam diplomatas e outros assessores internacionais. Em volta do tabuleiro doméstico e atrás do líder nacional, sentam-se figuras partidárias, parlamentares, porta-vozes das agências domésticas, representantes de grupos chave de interesses e os assessores políticos do próprio líder.

A teoria elaborada por Putnam debruça-se sobre a conexão entre as políticas interna e externa, procurando explicá-lo. A preocupação básica não é debater se é a política interna que influencia as relações internacionais ou o inverso. Na verdade, o que realmente ocorre, segundo Putnam, é que ambas se constituem mutuamente, uma determinando a outra e vice-versa. 0 importante seria determinar "quando" e "como" isso acontece. A pesquisa sugere que, nos processos de negociações internacionais: no primeiro momento, são utilizadas diferentes políticas daquelas que os governos chaves teriam adotado de forma isolada; e, no segundo, os acordos só são possíveis porque uma minoria detentora de poder, dentro de cada governo, defende, internamente, a política sendo demandada externamente (PUTNAM, 1988). Restaria, então, saber "como" e "quando" funcionaria esse processo.

É importante ressaltar que, ao contrário da análise de autores realistas e neorrealistas, que acabam desenvolvendo um argumento apolítico, onde os sistemas e os processos políticos não têm tanta importância, o autor defende que uma apreciação mais adequada dos determinantes internos da política externa e Conjuntura Global, vol. 5 n. 1, jan./abr., 2016, p. 168-188. 
das relações internacionais deve enfatizar a política: partidos, classes sociais, grupos de interesse (tanto econômico como não-econômico), legisladores e, até mesmo, a opinião pública e as eleições, e não apenas os funcionários executivos e os arranjos institucionais (PUTNAM, 1988, p. 432).

\section{PE e Eleições Presidenciais de 2014}

A análise aqui feita concentra-se nos três principais candidatos com maior número de intenções de voto: Dilma Rousseff (PT), Aécio Neves (PSDB) e Marina Silva (PSB). Os demais candidatos não apresentaram propostas suficientes para serem analisadas e comparadas entre si, porque muitos sequer apresentavam um tópico para a questão em seus programas de governo. A segunda seção do trabalho se dividirá de acordo com os candidatos, abordando os principais temas presentes nas falas e materiais apresentados pelos mesmos ao TSE em seus respectivos espaços, separadamente.

Cabe salientar também que pouco se utilizou os debates eleitorais em redes abertas de televisão, resultado da insuficiência de perguntas e respostas da totalidade de candidatos frente ao tema. Ao total foram assistidos cinco debates do primeiro turno, televisionados pela Rede Bandeirantes (01/08), Rede TV (07/09), CNBB/Aparecida (16/09), TV Cultura (22/09), Rede Record (28/09) e Rede Globo $(02 / 10)$. Posteriormente, do segundo turno, Band (14/10), SBT (16/10), Record $(19 / 10)$ e Globo (24/10).

\section{Aécio Neves}

O candidato de oposição propôs transformar o MERCOSUL em uma área de livre comércio que possibilite ao Brasil realizar novas parcerias com outros países, já que o bloco o impede de buscar novas alternativas. Perguntado se isso significaria o fim do MERCOSUL, o então Senador respondeu que não; significaria 
criar novas regras de libertação, para buscar parcerias com países a fim de que haja complementariedade na economia brasileira. Aécio ainda defendeu a retomada da integração regional, com liberalização comercial e a recuperação de objetivos originais do MERCOSUL, como flexibilizar as regras do bloco para avançar nas negociações com outros países:

[...] precisamos fugir desse alimento com o MERCOSUL e buscar parcerias com o mundo desenvolvido e que permitam parcerias com empresas brasileiras que hoje estão fora das cadeias globais de produção [...]. [...] a união com a União Europeia é essencial para nós recuperarmos o vigor de determinados setores da economia brasileira. ${ }^{5}$

Sobre o Itamaraty, defende sua "revalorização [...] na formulação de nossa política externa, subsidiando as decisões presidenciais".

O grande desafio que a nova política de comércio exterior enfrentará será o de promover uma crescente integração do Brasil no comércio internacional. É imperativo que nosso país deixe de ser um dos mais fechados do mundo e que seja definida uma estratégia de integração competitiva das empresas brasileiras às cadeias mundiais de valor. Somente assim desenvolveremos uma indústria e um setor de serviços competitivos. ${ }^{6}$

As principais diretrizes do candidato e seus aliados para o Comércio Exterior baseiam-se em uma integração competitiva do setor econômico brasileiro ao mundo para reduzir o atraso tecnológico da indústria e abrir caminho para um plano estratégico de modernização, compatível com a dinâmica do sistema econômico internacional.

Para o candidato, a criação de um Conselho Nacional de Política Externa poderia esbarrar com "as instâncias institucionais e políticas que também representam e interpretam a vontade popular", isso é, com o Itamaraty. O

5 TSE, Programa de Governo de Aécio Neves, Eleições 2014.

6 TSE, Programa de Governo de Aécio Neves, Eleições 2014. Conjuntura Global, vol. 5 n. 1, jan./abr., 2016, p. 168-188. 
candidato também acredita no potencial Brasil-EUA e ressaltou que isso não pode ser ignorado "por preconceitos ou desconfiança". "Um dos desafios das próximas décadas será expandir a oferta mundial de alimentos. Brasil e EUA têm duas das maiores e mais competitivas agriculturas do mundo e têm muito a ganhar com maior cooperação", diz. Para ele, o incidente da NSA produziu justificável mal-estar e que o governo dos EUA deve tomar medidas para superá-lo, mas não devemos ficar "reféns desse episódio". 0 ex-governador de Minas Gerais acredita que os dois países têm uma relação de complementaridade importante, mas que é preciso dar novos contornos. Para ele, é necessário diversificar as exportações brasileiras, reduzir as exportações chinesas de bens de consumo baratos e desenvolver parcerias em áreas como tecnologia e infraestrutura.

A China, maior parceira comercial do Brasil na atualidade, foi citada como preponderante nas relações bilaterais do Brasil. "A China é uma sociedade com cultura e organizações socioeconômicas diferentes e deve ser vista como tal, não para hostilizá-la, mas para melhor compreendê-la". Também, nas palavras de Aécio, "aos dois interessa um mundo estável e harmonioso, livre de hegemonias. Brasil e China, como dois grandes países em desenvolvimento e potências regionais, têm responsabilidade especial no contexto em que nos encontramos".

Majoritariamente o texto apresenta caráter econômico e desenvolvimentista, como exemplo de propostas para uma nova política de comércio exterior, buscando se articular com a política macroeconômica e com a política industrial, voltada para a recuperação da produtividade, da competitividade e da inovação. É citada, também, uma recuperação da competitividade e estímulo à maior e melhor inserção do país no comércio internacional, por meio de medidas voltadas à redução do "custo Brasil": ampliação do comércio exterior, retomada das negociações de acordos comerciais e ao apoio ao investimento externo de empresas brasileiras. Dentre outras propostas, seu plano de governo previa ações para facilitar o comércio exterior, 
reestruturando tarifas e reorganizando estratégias de negociações com países como a China, por exemplo, para aumentar a competitividade.

\section{Dilma Rousseff}

As diretrizes de Dilma abordaram manter o país trilhando o caminho da busca pelo protagonismo e do multilateralismo anteriormente aplicadas no governo Lula. Nas palavras dela,

a prioridade que conferimos a uma visão multilateral do mundo nos conduz e conduzirá a lutar pela reforma dos principais organismos internacionais, como a ONU, o FMI, o Banco Mundial, entre outros, cuja governança hoje não reflete a atual correlação de forças global. ${ }^{7}$

A ênfase dada na América Latina, como a integração da região, por meio de fomento do comércio e da integração produtiva, é baseada no MERCOSUL e atuais parceiros sul-americanos, além de afinar as relações com os países desenvolvidos como os Estados Unidos, o Japão e nações da União Europeia. Foi observada também uma priorização da integração financeira e de suas infraestruturas física e energética, com ênfase nas "relações com a África, com os países asiáticos" e "com o mundo árabe", assim como a China, sendo citada como o maior parceiro comercial do Brasil.

O plano PTista avaliou a priorização da integração regional envolvendo a América do Sul, América Latina e o Caribe como fomento do comércio e da integração produtiva e ênfase na integração financeira e de suas infraestruturas física e energéticas. A candidata propôs ainda reforçar ações para o fortalecimento dos blocos regionais MERCOSUL, UNASUL e a Comunidade dos Países da América Latina e do Caribe (Celac), sem discriminação de ordem ideológica. Dilma, frisando a defesa pelas reformas dos principais organismos internacionais, como a 
Organização das Nações Unidas (ONU), o Fundo Monetário Internacional, discorreu que o Banco Mundial e sua governança hoje não reflete a atual correlação de forças globais.

A integração regional aparece como prioridade da política externa da atual presidente, que busca, na cooperação Sul-Sul, "uma ordem mundial multipolar e menos assimétrica". "Durante séculos, os países da América do Sul estavam de costas uns para os outros, com os olhos voltados para a Europa e para os EUA. Essa realidade começou a mudar. Passos importantes foram dados nos planos econômico, comercial, político e de segurança com o fortalecimento do MERCOSUL e a criação da UNASUL" disse em entrevista à Revista Política Externa.

A candidata do PT colocou como compromisso dar continuidade ao aperfeiçoamento do BRICS como polo de estabilização da ordem mundial. "Creio que ninguém mais, hoje, questiona a importância do BRICS. [...] A criação do Novo Banco de Desenvolvimento e do Arranjo Contingente de Reservas foi reconhecida mundialmente como a mais importante iniciativa da economia global nas últimas décadas", afirma. Para Dilma, a função do bloco é abrir fronteiras com relações em continentes até "esquecidos", como a África, além de reforçar laços na Ásia. Nesse sentido, o BRICS ajudaria na capacidade político-diplomática "seja pela presença de membros permanentes do Conselho de Segurança da ONU, seja pela capacidade de diálogo de Brasil, Índia e África do Sul”.

Perguntada sobre a relação Brasil-EUA e a espionagem feita pela NSA, a presidente respondeu que a relação bilateral com os EUA é essencial e ainda há um enorme potencial de oportunidades que não se limitam só às ações do governo no que tange à cooperação em educação, ciência, tecnologia e inovação. Apesar de classificar a espionagem como "inaceitável", Dilma acredita que "tal atrito não deverá impedir nossos sinceros esforços para aprofundar essas relações bilaterais tão importantes".

Em relação à parceria com a China, a presidente classifica como otimistas as perspectivas para as relações entre os dois países, citando a "ampliação dos Conjuntura Global, vol. 5 n. 1, jan./abr., 2016, p. 168-188. 
investimentos recíprocos; o estímulo a exportações brasileiras de maior valor agregado; a cooperação espacial, educacional e em ciência, tecnologia e inovação; e a coordenação em temas da agenda política e econômica mundial". Dilma lembra ainda que a China é o principal parceiro comercial do Brasil desde 2009, mas considera que o país não é dependente de exportações chinesas. "Nossa política comercial sempre buscou diversificar as parcerias, justamente para evitar dependências. Isso nos permitiu atravessar a crise econômica de 2008 sem grandes abalos na balança comercial", diz.

Para a presidente, a política externa, como tantas outras, é uma política pública e, portanto, a ampliação de espaços democráticos de participação da sociedade civil junto ao governo é "sempre bem-vinda". Ela ressalta que o Itamaraty já vem desenvolvendo um esforço no sentido de ampliar a interlocução direta com a sociedade civil e que "a existência de organismos consultivos é sempre positiva".

Grupos econômicos de caráter cooperativo, segundo a candidata, beneficiaria o papel do Brasil como global player, no qual deveria ser fortalecido e aprimorado. Assim, de acordo com as diretrizes apontadas durante a campanha da coligação, o multilateralismo foi diretamente contraposto com a presença de blocos econômicos considerados fundamentais, como o MERCOSUL e a Alca.

\section{Marina Silva}

No programa de governo do então candidato Eduardo Campos o tema Política Externa não se fez presente no Sumário, surgindo como "Política de Defesa", no eixo denominado "Estado e a Democracia de Alta Intensidade"8, em um subtítulo enunciado "Política de Defesa: soberania democrática". O programa posteriormente apresentado por Marina não modificou essas propostas, mantendo as mesmas diretrizes que o ex-Governador.

8 Página 23 do Programa de Governo da Coligação Unidos Pelo Brasil. Conjuntura Global, vol. 5 n. 1, jan./abr., 2016, p. 168-188. 
O setor de Defesa foi privilegiado na coligação de Marina Silva. Investimentos em setores da base industrial voltados para a defesa brasileira, buscando recursos de iniciativa privada para a autonomia de avaliação, decisão e ação na defesa de sua soberania nacional. A integração regional do país é citada apenas no segundo eixo do programa, relacionada com economia e desenvolvimento sustentável. Em subtópicos como economia solidária e agricultura familiar, o programa sugeriu o aproveitamento econômico, de forma sustentável, para combater as desigualdades regionais que existem na América do Sul.

A Política Externa é vista como um serviço ao desenvolvimento, que projete no cenário internacional os produtos e serviços brasileiros e favoreça a inclusão de empresas nacionais nas cadeias globais de produção. Para a ex-Senadora, a participação do país nas instâncias de decisão internacionais deve se basear na defesa da paz, da democracia, dos direitos humanos e do desenvolvimento sustentável. Marina defende que o Brasil assuma posição proativa nas negociações sobre mudança climática e busque a inclusão da questão na agenda do G20.

Entre as promessas, a candidata afirmou que iria acelerar as negociações para o acordo MERCOSUL - União Europeia, propondo uma política de aproximação do MERCOSUL com a Aliança do Pacífico e promover o fortalecimento da UNASUL como organização de cooperação de políticas regionais. Para ela, o Brasil também precisa adotar uma agenda positiva para as relações com os Estados Unidos e atualizar os mecanismos de cooperação com a África. A candidata ainda tece sobre fortalecer a diplomacia pública brasileira e ampliar os meios para oferecer maior assistência aos brasileiros no exterior ${ }^{9}$.

No programa de governo, a equipe de Marina diz: "A política externa deve estar a serviço do desenvolvimento [...] e favorecendo a inclusão de nossas empresas nas cadeias globais de produção". Sublinha que "a participação do país nas instâncias de decisão internacionais legitima-se pela defesa inequívoca da paz,

9 Disponível em: <http://agenciabrasil.ebc.com.br/internacional/noticia/2014-09/veja-propostas-dos-candidatos-presidencia-parapolitica-externa> 
da democracia, dos direitos humanos e do desenvolvimento sustentável". Há preocupação em se relacionar com países que preservam os direitos humanos e a sustentabilidade. As diretrizes explicitam que o Brasil deve envolver "Chile, Peru, Colômbia e México". Em outros termos, aproximar-se da Aliança do Pacífico, bloco latino-americano com viés mais pragmático que o do MERCOSUL. Ao falar no MERCOSUL, o documento defende que o Brasil deixe de ceder à pressão da Argentina e faça acordo de livre comércio com a União Europeia. Explicitamente, fala: "Abrir as portas do Pacífico". Outro tópico: "Reacender o dinamismo nas trocas com os Estados Unidos e com a União Europeia. Fundar novos padrões de comércio com a China."10

A candidata do PSB (Partido Socialista Brasileiro) aposta no combate à suposta estagnação do MERCOSUL, reforçando a necessidade de investir em negociações com outros países. "O MERCOSUL não tem cumprido bem o desígnio original de constituir uma modalidade de 'regionalismo aberto'”, escreve em seu programa de governo. Marina Silva propõe uma política de aproximação do MERCOSUL com a Aliança do Pacífico e também destaca a necessidade de acelerar as negociações para o tratado de associação entre o bloco e a União Europeia. Para ela, "salvo um par de acordos de livre comércio com mercados inexpressivos [...] As tratativas iniciadas há mais de uma década com vistas à associação com a União Europeia permanecem inconclusas", completa. Para a candidata, a construção de infraestrutura para internacionalizar a economia brasileira deve ter "receptividade e apoio à cooperação empresarial". Para além do caráter econômico, a presidenciável acredita que a integração continental deve também se expandir para questões socioambientais e culturais.

De acordo com a coligação, a participação do Brasil no BRICS cumpre necessidade de articulação internacional na direção de um mundo mais multipolar. "A identificação de interesses comuns do Brasil com outros países do BRICS contribui para maior equilíbrio na geopolítica atual, fortalecendo países

10 Disponível em: <http://zh.clicrbs.com.br/rs/noticias/eleicoes-2014/noticia/2014/09/como-os-principais-candidatos-a-presidenteprojetam-a-politica-externa-4592515.html> 
emergentes sub-representados nas instâncias internacionais criadas após a 2a Guerra Mundial", elogia. No entanto, Marina Silva ressalta a importância de se reconhecer as diferenças nas agendas econômica, política, cultural e ambiental, assim como na pauta de direitos humanos e liberdades civis de cada um dos países do bloco. Para ela, também é preciso um olhar mais cuidadoso com a África. "Não bastasse o reconhecimento ao legado histórico, étnico e cultural que nos foi transmitido em séculos de história, a aproximação com o continente africano permite a identificação de vasto leque de oportunidades para empresas brasileiras", destaca.

De acordo com o plano PSBista, as relações com os Estados Unidos carecem de atualização, já que houve uma queda da participação brasileira no mercado norte-americano, um dos principais destinos das nossas manufaturas. Ela acredita na necessidade de "desenvolver um diálogo maduro, equilibrado e propositivo com Washington, que não dramatize diferenças naturais entre parceiros com interesses econômicos e políticos reconhecidamente amplos".

A candidata coloca como prioridade fundar novos padrões de comércio com a China, diversificando a pauta de exportação do Brasil. Para ela, é preciso estimular a "substituição das indústrias de baixo custo por indústrias intensivas em conhecimento". Além disso, ressalta as taxas de câmbio das moedas, que têm trazido dificuldades ao Brasil. "Convém empenhar-se para que investimentos chineses atendam às nossas expectativas de estabelecimento de parcerias, utilização de insumos locais, criação da capacidade de pesquisa e desenvolvimento e contratação de mão de obra e de executivos brasileiros", aponta.

Finalmente, Marina reitera a colocação de outras vozes no debate sobre os rumos de ação externa, não sendo necessário criar um conselho com atribuições paralelas, mas revalorizar o Ministério das Relações Exteriores. "Propomos aumentar a porosidade do Itamaraty aos influxos externos, seja do Estado, seja da sociedade, o que começa a ser feito pela gestão atual da Casa de Rio Branco", cita. 


\section{Considerações finais}

A pesquisa pretendeu analisar os planos de governo dos presidenciáveis Aécio Neves (PSDB), Dilma Rousseff (PT) e Marina Silva (PSB), apresentados para a disputa ao cargo, em 2014. Com base na análise qualitativa das propostas de governo dos três principais candidatos às Eleições Presidenciais de 2014, pôde-se averiguar algumas questões distópicas quanto à Política Externa. Ao passo que as diretrizes acentuadas pelo candidato do PSDB, Aécio Neves, priorizaram a reaproximação com os grupos desenvolvidos, como Estados Unidos da América (EUA) e a União Europeia, desprendendo o comércio brasileiro das amarras do MERCOSUL, assim como as de Marina Silva, do PSB, o programa de governo da candidata Dilma Rousseff (PT) visava a expansão e estreitamento das alianças entre os países da América Latina, bem como o de grupos de países em desenvolvimento, como o BRICS.

Em um primeiro momento, avaliou-se a correlação da (não) presença da Política Externa como Política Pública, a exemplo da Saúde e da Educação, temas tão recorrentes nos discursos e debates entre os candidatos. As falas dos presidenciáveis em redes de televisão, durante os debates promovidos pelas emissoras abertas, quase em nada contribuíram para essa pesquisa, visto que pouco se comentou a respeito do assunto Política Externa, salvo em tópicos como o Programa Federal Mais Médicos. Mesmo que presentes nos Planos de Governo, as questões de PE somente foram debatidas quando questionadas por órgãos especializados, como a Revista Brasileira de Política Externa, não contribuindo de forma significativa na escolha do candidato por parte da população.

$\mathrm{Na}$ segunda seção, foram analisadas as propostas de governo, pronunciamentos dos candidatos e opiniões de analistas sobre quais as diretrizes que cada plano apontava de acordo com cada campanha, analisando, em específico, ideias presidenciáveis quanto a agendas de grande importância para o Brasil, como o MERCOSUL, BRICS, América Latina, Cooperação Sul-Sul e relações bilaterais com a China, Estados Unidos e União Europeia. 
Os candidatos oposicionistas apresentaram propostas com maiores diretrizes de caráter econômico, nos quais citam as relações com os BRICS, União Europeia e Estados Unidos como essenciais para o desenvolvimento do Brasil. A cooperação tecnológica com países desenvolvidos retomaria em grande escala as relações Norte-Sul vigentes sob regime neoliberal. Do outro lado, o governo de situação prioriza parcerias com países em desenvolvimento, parcerias regionais e o estreitamento das relações dentro do MERCOSUL.

Assim, o trabalho concluiu que a Política Externa tem fraca influência nos discursos - resultado das correntes de não divulgação da posição brasileira com o exterior. Os candidatos, seguindo a tradição, não inseriram a política externa em suas principais propostas de governo majoritariamente divulgadas, apenas sinalizando direções, que se apresentam de forma variada de candidato para candidato, quando questionados por órgãos especializados e de pouca circulação entre as grandes massas.

\section{REFERÊNCIAS}

CARDoso, A. F. Política Externa e Opinião Pública. PUC. Disponível em<http://www.pucsp.br/neamp/artigos/artigo_36.html $>$ acesso em: $<17$ de outubro de 2015>;

CERVO, A. L; BUENO, C. História da Política Exterior do Brasil. Universidade de Brasilia, 2012.

DEFESA NET. Eleição 2014- política externa evidencia diferenças entre Dilma e Aécio. Disponível em: < http://www.defesanet.com.br/geopolitica/noticia/17057/ELEICAO-2014--Politica-externa-evidencia-diferencas-entre-Dilma-e-Aecio/>; Acesso em 02/12/2015;

GARCIA, J. C., PORTARI, D. Política externa é uma política pública como as demais. Está sujeita à expressão das urnas. Entrevista com Celso Amorim, 2010. Disponível em:<http://www.ipea.gov.br/portal/index.php?option=com_content\&view=article \&id=6458 $>$ acesso em: $<6$ de novembro de 2015 $>$.

GERCHMANN, Léo. Em Zero Hora. Como deve ser a política externa de Dilma e Aécio. Disponível em: <http://zh.clicrbs.com.br/rs/noticias/eleicoesConjuntura Global, vol. 5 n. 1, jan./abr., 2016, p. 168-188. 
2014/noticia/2014/10/como-deve-ser-a-politica-externa-de-dilma-e-aecio4623835.html > <Acesso em 03/12/2015>;

GOMES, Vinicius. Em Revista fórum. A política externa nas eleições de 2014. Disponível em: <http://revistaforum.com.br/digital/166/politica-externa-dospresidenciaveis/><Acesso em 03/12/2015>;

KAPPAUN, A. 0, SANTOS, V. C. A interação entre a política interna e a política externa: a teoria dos jogos de dois níveis e os temas sociais na política externa brasileira. Associação Brasileira de Relações Internacionais Instituto de Relações Internacionais - USP, $3^{\circ}$ Encontro Nacional ABRI, 2011. Disponível em:<http://www.proceedings.scielo.br/scielo.php?script=sci_arttext\&pid=MSC00 $00000122011000100005 \& \operatorname{lng}=e n \& n r m=a b n>$. Acesso em: $<16$ de novembro de 2015>;

KAPPAUN, A. 0., SANTOS, V. C. A interação entre a política interna e a política externa: a teoria dos jogos de dois níveis e os temas sociais na política externa brasileira. In: $3^{\circ}$ Encontro Nacional ABRI 2001, 3. São Paulo, 2011.

KEOHANE, R. O. \& NYE, J. S. Power and Interdependence. 3rd ed. New York: Longman, 2000;

KEOHANE, Robert O.; MILNER, Helen V. Internationalization and domestic politics. Cambridge University Press, 1996.

LAFER, C. A identidade internacional do Brasil e a política externa brasileira. $2^{\underline{a}}$ ed. São Paulo: Perspectiva, 2004;

LIMA, M. R. S. 2002. Foreign Policy and Democracy: A Preliminary Analysis of the Brazilian Case. Trabalho apresentado na Convenção anual da Associação Internacional de Sociologia, realizada em Nova Orleans, de 24 a 27 de março. Disponível em:<http://www.isanet.org/noarchive/lima.html $>$ acesso em: $<26$ de outubro de 2015>;

MATEUS, S. Estrela (de)cadente: uma breve história da opinião pública. Disponível em:<https://www.academia.edu/3248843/Estrela_De_Cadente_uma_breve_hist\% C3\%B3ria_da_opini\%C3\%A3o_p\%C3\%BAblica $>$ acesso em:< 3 de novembro de 2015>;

MILANI, C. R. S., PINHEIRO, L. Política externa brasileira: os desafios de sua caracterização como política pública. Contexto int., Rio de Janeiro , v. 35, n. 1, p.1141, June 2013.2 Disponível em:<http://www.scielo.br/scielo.php?script=sci_arttext\&pid=S0102-

$85292013000100001 \& \operatorname{lng}=e n \& n r m=i s o>$. Acesso em: $<10$ de novembro de 2015>;

MILNER, H. Interest, Institutions and Information: Domestic Politics and International Relations. Princenton: Princeton University, 1997;

Conjuntura Global, vol. 5 n. 1, jan./abr., 2016, p. 168-188. 
MILNER, H. V., Dustin H. Public Opinion and Foreign Aid: A Review Essay (April 26, 2013). International Interactions, Volume 39, Number 3, Forthcoming. Disponível em:<http://ssrn.com/abstract=2256916>, acesso em:<17 de outubro de 2015>;

O ESTADO DE SÃO PAULO. Dilma e Aécio têm divergência programática: Confronto dos candidatos expõe projetos de País antagônicos na economia e na política externa. Disponível em:<http://politica.estadao.com.br/noticias/eleicoes,dilma-eaecio-tem-divergencia-programatica,1572578> Acesso em: $<20$ de novembro de 2015>.

PECEQUILO, C. S. Política externa, política do Brasil: a escolha entre Aécio e Dilma é também uma decisão sobre qual papel o País deve exercer no mundo. Disponível em:<http://www.cartacapital.com.br/blogs/blog-do-grri/politica-externapolitica-do-brasil-4400.html $>$ acesso em:<18 de novembro de 2015>;

POLÍTICA EXTERNA. O mundo dos candidatos. São Paulo: HMG Editora. Vol. 23 no 1. Jul/ago/set 2014.

PUTNAM, R. D. Diplomacia e política doméstica: A lógica dos jogos de dois níveis. REVISTA DE SOCIOLOGIA E POLÍTICA V. 18, № 36: 147-174 JUN. 2010. Disponível em: < http://www.scielo.br/pdf/rsocp/v18n36/10.pdf> acesso em 18 de novembro de 2015;

REDE BRASIL ATUAL. Eleições colocarão em disputa duas visões divergentes sobre política externa. Disponível em: http://www.redebrasilatual.com.br/eleicoes2014/eleicoes-presidenciais-colocarao-em-disputa-duas-visoes-divergentes-depolitica-externa-2896.html; Acesso em: <03/12/2015>;

SANCHEZ, M. R., SILVA, E. C. G. da; CARDOSO, E. L; SPÉCIE, P. Política Externa como Política Pública: uma análise pela regulamentação constitucional brasileira (19671988) Rev. Sociol. Polít., Curitiba, 27, p. 125-143, nov. 2006. Disponível em:<http://www.scielo.br/pdf/rsocp/n27/09.pdf > acesso em:<13 de outubro de 2015>;

TSE. Calendário eleitoral $2014 . \quad$ Disponível em:<http://www.tse.jus.br/eleicoes/eleicoes-anteriores/eleicoes2014/calendario-eleitoral>, acesso em:<16 de outubro de 2015>;

TSE. Plano de governo Aécio Neves. Disponível em: < http://inter01.tse.jus.br/divulga-cand2014/proposta/eleicao/2014/idEleicao/143/UE/BR/candidato/280000000085/i darquivo/229? $x=1404671991000280000000085>$;

TSE. Plano de governo Dilma Rousseff. Disponível em: < http://inter01.tse.jus.br/divulga-cand- 
2014/proposta/eleicao/2014/idEleicao/143/UE/RS/candidato/210000000003/i darquivo/14>; <Acesso em 01/12/2015>;

TSE. Plano de governo Marina Silva. Disponível em: < 2014/proposta/eleicao/2014/idEleicao/143/UE/BR/candidato/280000000121/i darquivo/363? $\mathrm{x}=1410369872000280000000121>$; <Acesso em 01/12/2015>;

WITTKOPF, E.R. Faces of Internationalism: Public Opinion and American Foreign Policy. Durham and London: Duke University Press, 1990;

VISENTINI, P. F. A projeção internacional do Brasil; 1930-2012. Rio de Janeiro: Elsevier, 2013. 